\title{
Transformation of the Higher Education System of Ukraine and Algeria in the Context of The Impact of the Fourth Industrial Revolution
}

\author{
Anna Levchenko ${ }^{1 *}$, Dmytro Plynokos ${ }^{2}$, Ilona Tsarenko ${ }^{3}$, Abdelmalek Boussadia ${ }^{4}$, and Seyf-Eddine Bouaita ${ }^{5}$ \\ ${ }^{1}$ Economic Sciences, Economy, Management and Commercial Activity Department, 25006 Kropyvnytskyi, Ukraine \\ ${ }^{2}$ Economic Sciences, Entrepreneurship, Trade and Exchange Activities Department, 69063 Zaporizhzhia, Ukraine \\ ${ }^{3}$ Economic Sciences, Economy, Management and Commercial Activity Department, 25006 Kropyvnytskyi, Ukraine \\ ${ }^{4}$ Economic Sciences, Entrepreneurship, Trade and Exchange Activities Department, 69063 Zaporizhzhia, Ukraine \\ ${ }^{5}$ Economic Sciences, Economy, Management and Commercial Department, 25006 Kropyvnytskyi, Ukraine
}

\begin{abstract}
The paper focuses on the presence of a strong relationship between the level of education and unemployment in the EU and the OECD countries. A graphic confirmation of the change in the relative wages of employees depending on the level of education is given. The authors noted that in recent years there has been an expansion of the mass character of higher education, however, the latter has undergone transformations, in particular, the emergence of universities of a new format - University 21, School 35 and others. The author identifies the key features inherent in the field of higher education under the influence of the 4th Industrial Revolution. Of particular importance are the results on the existing imbalances in the field of higher education in the context of the transition to the new stage in the development of society - the 4th Industrial Revolution and the existing strategic gaps in the economies of the countries of the world depending on the level of development. The most optimal strategy for eliminating the existing imbalances in the field of higher education in the context of the 4th Industrial Revolution for the transition countries is proposed.
\end{abstract}

\section{Actuality}

The system of higher education in modern conditions of deepening the innovative orientation of the world's economies and internationalization processes is a unique area of state regulation, which can accelerate the economic development of the country, the pace of its development.

There is evidence of a direct link between education and employment and an inverse relationship between unemployment in the OECD and the EU. This phenomenon is connected with the fact that without education a person cannot be realized in the labour sphere, finding a job, which affects not only its way of life, but also causes economic and social losses to the state. Moreover, based on the analysis of OECD reports, we see that the advantage of higher education is inherent in both individuals who receive it and the state as a whole, which explains the trend of widespread higher education in the world in general and in Ukraine and Algeria in particular.

However, scientists state that support for the expansion of the mass of higher education has been justified by the governments of various countries as a necessity to solve the problem of youth unemployment. However, in the coming decades, the problem of "reeducation", is a large number of young unemployed people with higher education, will appear for political power as the most important and most difficult aspect of its activities. And these difficulties are generally due to the fact that "the system of mass higher education, with the exception of a few elite universities, can no longer be considered as one that provides social mobility" [1, p.192-193].

The sharp increase in the number of higher education institutions (different levels of accreditation based on different forms of ownership) with a low level of teaching staff and underdeveloped material, laboratory, classroom facilities has negatively affected the quality of training - this quality is low and the state diploma of higher education now it is not always a criterion of professional competence and a guarantee of success in the labour market. The fact that there are many young people among the entrants, who at the time of admission have not yet decided on the choice of specialty they would like to receive in the process of study, also adds to the problems. The specialists are well acquainted with the current problems of enrolment of applicants, as most of them submit documents to several universities, to different faculties, to different specialties and to the last are not able to make a choice. In this case, of course, the final decision is often influenced by completely random factors. That is, for many it is not important to get a specific specialty, but the very fact of being in the university is significant. Moreover, the introduction of external evaluation for admission to the university has further deepened this problem, because, according to the analysis of data from the introductory info platform, future students do not care what specialty to master, the main thing is to 
enter to the university. and the development of professional skills and abilities.

In addition, in contrast to OECD countries, where the salaries of specialists with higher education are 2-4 times higher than those with basic education (Fig. 1), Ukraine is characterized by a maximum increase in wages by $30 \%$, which indicates the inefficiency of the state regulation of higher education in Ukraine and actualization of changes in the conceptual foundations of such regulation at the present stage. The same situation is be seen in Algeria, in particular $40 \%$ by the last 10 years [2].

The field of higher education is a powerful catalyst for the situation in the country, so its development is influenced by the state of political and economic situation, which in turn affects the efficiency of the entire higher education system, the image not only of higher education but also the level of competitiveness in the labour market, both nationally and internationally, given the openness of the world's economies.

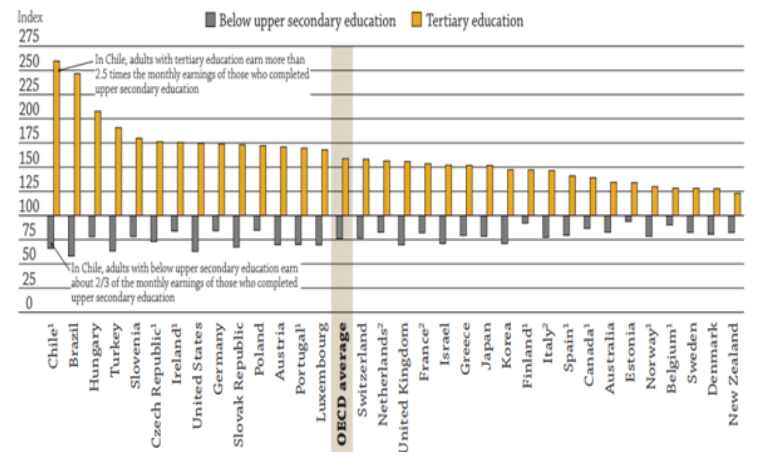

Fig. 1. Relative wages of employees by level of education (2012) 25-64 years old with income from employment; upper middle $=100[3]$

At the present stage of transformations, we consider it expedient to classify Ukraine and Algeria as a transit economy, which is characterized by structural changes aimed at the development of market institutions, economic liberalization, democratization of all processes in the economy, transition from industrial to post-industrial society (a society in whose economy the priority has shifted from the predominant production of goods to the production of services), research, organization of the education system and improving the quality of life, in which the class of technical specialists has become the main professional group and, most importantly, in which the introduction of innovations is increasingly dependent on the achievement of theoretical knowledge.

Post-industrial society presupposes the emergence of the intellectual class, whose representatives at the political level act as consultants, experts or technocrats "[4, pp. 102-118].

The Third industrial revolution, also called the digital revolution, began in the second half of the twentieth century on the creation of digital computers and the further evolution of information technology. Of course, today the most developed countries operate in the era of the Third Industrial Revolution.

According to Bell, "post-industrialism" is characterized by five feat ures: the transition from the production of goods to the production of services; predominance among employees of the "class" of professionals and technicians; the leading role of theoretical knowledge as the basis of innovation in economics, politics and social structure of society; focus in the future on methods of control and assessment of possible directions of technology development; decisionmaking on the basis of a new "intellectual technology" [4, P. 102-118].

All these features are inherent in the third stage of development of society, the era of informatization, the transformation of which is aimed at the reform processes of all sectors of the economy, including higher education in most countries with economies in transition. After all, transformations and reforms in the field of higher education are aimed at achieving a change of specialties, the ability to meta-qualify, the elimination of boundaries in the educational space, the need and access to lifelong learning, i.e to move from mass education to universal.

Thus, today, Ukraine is one of the countries with a strategic gap of the first level (GAP 1) in the development of higher education. Instead, when all the processes of reforming Ukraine are aimed at bridging the strategic gap of the first level (GAP 1), the developed countries move to a new stage of development - the Industrial Revolution 4.0, which features the mass introduction of cyber physical systems into production.

\section{The basis of Industrial Revolution 4.0 and its impact}

According to the WEF founder Klaus Schwab, the Industrial Revolution 4.0 is blurring the boundaries between the physical, digital and biological spheres. It is assumed that these cyber physical systems will be integrated into a single network, communicate with each other in real time, self-tune and learn new patterns of behaviour; will be able to build a production process with fewer errors, interact with manufactured goods and, if necessary, adapt to new consumer needs. The first steps in the world towards a new industrial revolution were cloud technologies, the development of Big Data collection and analysis methods, crowdsourcing, biotechnology, unmanned vehicles and medicine based on 3D printing, cryptocurrency Bitcoin and Blockchain technology.

The fourth Industrial Revolution was named industry 4.0. This term was first introduced at the German industrial fair in 2011 in Hanover. During this period, Germany approved two state programs: "Platform for Industry 4.0" and "Industry 4.0", both programs aimed at the strategic development of industry in the country (Germany: Industry 4.0).

The leading direction of these programs was the development of technologies and the Industrial Internet based on global communications. The key leitmotif of Industry 4.0 is total digitalization, the development of flexible production, the creation of "digital twins", the creation of cyber-physical systems (CPS), the unification of virtual and real worlds, augmented 
reality technologies, artificial intelligence (the New Industrial Revolution ).

To date, such programs have already been developed and are actively implemented in many countries of the world, such as the USA, the Great Britain, France, Belgium, Japan, etc. (Horizon 2020; Factories of the Future). For example, in Germany, the Industry 4.0 program is one of 10 future projects with strategic competitiveness improvement, and programs aimed at developing research activities in the industrial sector (Fraunhofer Program) are being implemented.

Australia is implementing a program, which is aimed at the developing the cooperation between academic organizations and industrial organizations to conduct the joint research projects with the aim of commercializing the innovative developments (Industry and Innovation Program).

In Japan, the Society 5.0 concept is being implemented, which is a continuation of the Industry 4.0 program, expanding it and adding a socio-cultural component to the industrial development, that is, it considers the solving of social problems through the integration of physical and cyberspace (From Industry 4.0 to Society 5.0 ).

According to the Club of Rome Report presented in 2017, despite the economic growth of the last 30 years in developed countries, society faces the following challenges: inequality, unemployment and climate change.

The gap between rich and poor is widening, millions of people are out of work, and real wages in many countries continue to fall, which can be closed by accelerating economic growth.

However, as Graham Maxton and Jorgen Randers point out, to continue the current path of development of the world economy is not only wrong, but also extremely unwise, because it will only worsen the problems of the world. According to them, the way out of the situation is to rethink the definition of paid work, fair taxation of business, restrict trade if necessary, introduce an unconditional basic income for the poorest third of the population and increase the duration of paid leave.

The impact of the Industrial Revolution 4.0 can be traced in the field of higher education with the emergence of a new format of universities - University 21, School 35 and others, which provide new approaches to the learning process, project-oriented methods, lack of teaching staff, universities in its usual form. All these changes to transform existing higher education systems into a new format are reflected in the strategic gap of the second level (GAP 2) that developed countries have at the present stage.

Moreover, the transformational transformations into New Format Universities within the Industrial Revolution 4.0 are based on the fact that such institutions should contribute to the development of society and the market, while based on the reduction of dependence on public funding. That is, they are gaining more and more social significance and financial autonomy.

Higher education within the Industrial Revolution 4.0 is based on the following components:
1. Change of organizational structure: change of business models; new format of faculties and departments; expansion of interdisciplinarity;

2. Change of accreditation procedure: new conditions of accreditation; "Floating" educational programs; training within the framework of accelerated innovative development;

3. Digital culture: the development of the diversity of the digital life cycle; new psychological distances (education without geographical borders, spaces); new forms of social communication; globalization of education; "Web education"; change of all types of information; problem-solving training; teacher - a guide to finding information.

4. Changing teaching methods: new approaches in teaching; new educational infrastructures; digital rights management.

5. Changes in learning: learning through distance platforms; new training infrastructures; personalized learning.

6. Individualism of learning through the model "Do it yourself" (DIY education).

Thus, while the reform process eliminates GAP 1 to achieve the level of development of developed countries, the latter, trying to move to the next stage, eliminate GAP 2, hence, as a result, Ukraine, like and Algeria after a certain period (T1) will in any case have strategic gap with developed countries in general and in higher education in particular.

Graphically we have the following in the form of fig. 2.

Therefore, in order to eliminate the disparity in the higher education system that may arise over a period of time (T1), it is necessary to develop a mechanism to ensure the competitiveness of higher education, which would not only eliminate GAP 1 , but also to address the strategic gap of level 2, as a result, it will not only enable the implementation of effective reforms, but also help reduce the timeframe for achieving them, because in the transition to the Industrial Revolution 4.0, the speed of response to change, turbulence of the existing environment and accelerated innovation will be key.

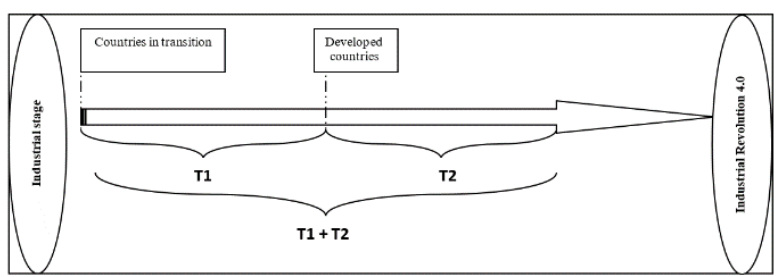

Fig. 2. Time chains of elimination of disparities in the field of higher education under the prism of the transition to the new stage of development of society - the $4^{\text {th }}$ Industrial Revolution

Therefore, the higher education system of Ukraine and Algeria, having strategic reserves, must at the present stage develop a new strategy aimed at trends and trends in higher education under the influence of the Industrial Revolution 4.0, rather than the transformation of the post-industrial stage of development. 
Moreover, the University of a new format, modifies such components as teaching, research, in particular: 1. (Teaching 4.0): textbooks, instruction and training provided by teachers; acquaintance with mass open Internet courses (MOOCs); cultivation of innovative methods; blended learning.

2. (Study 4.0): open innovation; evolutionary and revolutionary innovations; new research and development developments related to technical progress; reduction of innovation cycles.

3 (Services 4.0): university as a platform (UaAP); education as a service (EaaS); internationally related programs.

Previously, we have already analyzed the state of Ukraine's higher education system in the international aspect, where we studied the most popular assessment systems, among which there are ratings. Despite the fact that rating is one of the most popular methods of assessment, we consider it necessary to note the following:

1) the existing international rating systems provide for a balanced assessment of the results of various activities of universities with the dominance of the weight of achievements in research and educational activities. At the same time, improving, international methods are expanding in the direction of such components as: teaching and learning, research activity, internationalization, the availability of regional and socially-oriented programs, ie, as a result we note that methodological approaches are variable given the time requirements. their advantage over other approaches to evaluation;

2) the advantage is the focus of ratings on the assessment of consumers of educational services and employers, despite the likelihood of subjectivity;

3) among the shortcomings should be noted - a high probability of inaccuracy of data: on the websites of universities and organizations often lack information on higher education and science;

4) the lack of ratings is also a fairly high degree of subjectivity in determining the weight of the components of the assessment within the integrated assessment;

5) the bases of comparison in the rationing of the components of the integrated assessment are quite contradictory.

Thus, in determining the level of competitiveness of the assessment based solely on ranking, it is advisable to conduct a comprehensive assessment is not enough informative indicator.

\section{SWOT-analysis}

Therefore, we consider it necessary, with the help of SWOT-analysis, to analyze the main trends, prerequisites and consequences of higher education in Ukraine, to position the strengths and weaknesses of the national higher education system, as well as its threats and opportunities.

SWOT-analysis is one of the most popular methods of strategic management, formed as an abbreviation of four English words: Strengths, Weaknesses, Opportunities and Threats.

This method can be used to study the external and internal environment of any object of the economic system, including the higher education sector.

As a result, the following main points should be highlighted:

- Strengths: quite strong intellectual potential of both research and teaching staff and students, a wide network of universities in the country, which increases the availability of higher education among its consumers, facilitating the possibility of continuing education in European higher education institutions in connection with Ukraine's accession the $19^{\text {th }}$ May in 2005 at the conference in Bergen to the "Bologna Process", the agreements of Ukraine on legal aid, abolishing the requirement of legalization of official documents on education, the possibility of studying for double degree programs with the European universities.

- Weaknesses: low level of funding for education, which reduces the motivation of research and teaching staff, as well as weak interaction with employers, which hinders the effective transfer of knowledge, problems with employment of graduates.

- Opportunities: participation in international grant programs and academic mobility, as strengthening activities within the framework of international cooperation and involving the academic community in updating the processes taking place in the national economy, providing educational services to foreigners (increasing the number of foreign students);

- Threats: demographic crisis, macroeconomic processes in the economy, which have a negative effect on the scientific and technological potential and living standards of the population - the ability to obtain higher education, increasing competition from the European universities.

It was stated that today the greatest threat to the further development of the domestic competitiveness of higher education in Ukraine, given the innovative transformations and strengthening of internationalization, is the growth of competition from European universities, a decrease in the potential contingent in connection with the external independent testing, the inconsistency of the material base with the transformational changes in the sphere of higher education, incompatibility of curricula, complexity their adaptation to the European and lower wages of the teaching staff poses a threat to the personnel security of national universities.

\section{The current strategies of development the higher education system in the context of the Industrial Revolution 4.0}

Thus, in the system of higher education in Ukraine, the strengths of the internal environment are dominated by the weakness, and the opportunities of the external environment are threats. 
In this case, the recommended strategy is "Maxi-Maxi" - to use the strengths of the higher education system to realize the external opportunities. It consists in taking active steps to strengthen its position in the educational services market, including external, that is, increasing its share, diversifying products - opening the new specialties, providing paid services, creating an environment for science parks based on universities, commercializing scientific developments, support the generation of new ideas and the introduction of English-language teaching to increase the degree of internationalization of educational services. All this can be done with the help of an effective mechanism of state regulation of ensuring the competitiveness of higher education.

The current trends in economic processes, which are becoming increasingly turbulent, require, more and more often, the use of a wide range of mathematical techniques and tools to justify management decisions to determine the direction of further development of a particular activity. An important role is played by the methods of strategic analysis and forecasting, with the help of which, with a higher probability, it is possible to forecast indicators for the future.

To this end, we decided to perform a correlationregression analysis of the final position of the U21 rating and its components to identify the most significant indicators.

To predict the factors influencing the final position of the country within the international rating, four main components of the rating were taken: the component "resources"; the "environment" component; the "communication" component; component "issue".

\section{The study of empirical data}

As a result of the study of empirical data, we have the opportunity to build a functional relationship between them and, as a result, to make a forecast for the future.

The general position of the rating, which depends on a number of factors, can be expressed by nonlinear multiple regression. Estimates of the coefficients of which are calculated using the least squares method in matrix form.

As a result, we have built a mathematical model that looks like this:

$$
\begin{gathered}
\mathrm{y}=0.2387+0.2146 \times 1+0.2115 \times 2,+0.2152 \times 3+ \\
0.4315 \times 4, \text { where }
\end{gathered}
$$

$\mathrm{y}$ is the overall position in the $\mathrm{U} 21$ rating;

x1 - component "resources";

x2 - component "environment";

x3 - component "connection";

x4 - component "issue".

Forming the structure of the regression model, on the one hand, should include all factors that have a statistical impact on the indicator, and on the other hand, take into account the need for linear independence between factors (in the presence of approximate linear dependence between at least two factors). between them multicollenarity).
The using of the Farrar-Glober method made it possible to establish the presence of multicollenarity in the model. Verification using the $\chi^{2}$ test showed the presence of general multicollinearity, with a reliability of $\mathrm{p}=0.96$.

The analysis of the correlation matrix allowed us to draw the following conclusion: there is a close relationship between the factors $\mathrm{x} 1$ and $\mathrm{x} 3$, as well as $\mathrm{x} 1$ and $\mathrm{x} 4$. In addition, it should be noted that the factor $\mathrm{x} 4$ has the highest level of influence on the value of the indicator y $(\operatorname{ryx} 1=0.92$, ryx $3=0.92$, ryx $4=0.96)$ ).

As a result, in order to eliminate multicollenarity, we consider it necessary to remove the factors $\mathrm{x} 1$ and $\mathrm{x} 3$ from the regression model.

Due to the test, the value of $\chi 2$ was obtained, within which we observe that the multicollinearity persisted, but its value decreased slightly. Next, we perform a ttest to determine the significance of the regression coefficients, which showed that all the parameters of the regression model are positive, ie significant (none of the factors can be removed from the regression model).

According to the results of verification by Fisher's criterion, a model was obtained that is adequate to the statistical data $(\mathrm{F}=80,685$, Fcrit $=1,045)$.

Based on the calculations of the mathematical model, we conclude that the most significant components that should be considered in the development of strategic priorities are:

- the share of female students in higher education;

- the share of women in the teaching staff of universities;

- data quality assessment. (For each quantitative series, the value is 2 if the data is available to accurately define the variable; 1 if there is some data related to the variable, but some informed adjustment is required; and 0 otherwise);

- the percentage of students studying in private institutions and the percentage of students who obtain the educational qualification level "Master";

- the political environment of the country and the level of regulatory support;

- the level of financial autonomy of state universities;

- the degree of satisfaction of the higher education system with the needs of a competitive economy;

- number of published articles of universities;

- the number of published articles of universities per capita;

- the number of universities in the country included in the Shanghai ranking;

- the degree of enrollment in universities as a percentage of the number of persons who received secondary education during the last five years;

- percentage of the population aged 25-64 with higher education;

- number of researchers (full-time equivalent) per 1 million population;

- the unemployment rate among people with higher education aged 25-64 compared to the unemployment rate for people with incomplete or secondary education without higher education.

The above complements the preliminary analysis and allows to determine the main strategic priorities for the 
development of a strategy to increase the competitiveness of higher education (Fig. 3)

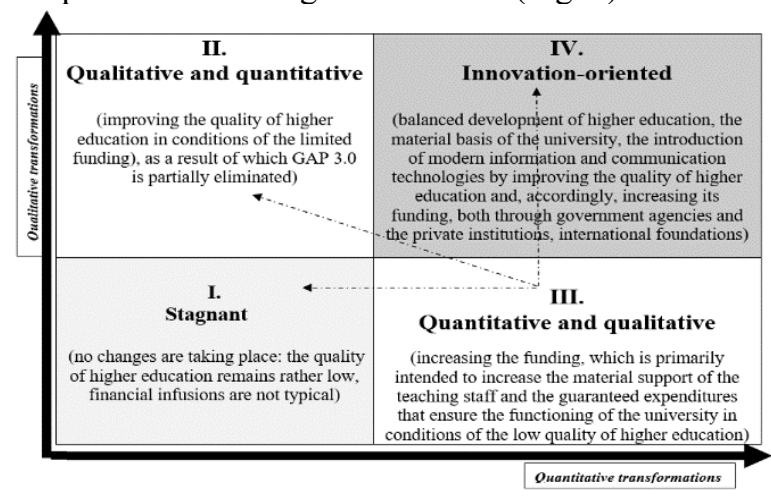

Fig. 3. Matrix of strategic priorities

Selection of strategic priorities of state regulation of competitiveness of higher education, which, in contrast to the existing ones, are based on possible scenarios of regulatory influence that determine the development strategy:

1) stagnant (no changes are taking place: the quality of higher education remains quite low, financial infusions are not typical);

2) qualitative and quantitative (improving the quality of higher education in conditions of limited funding), as a result of which GAP 3.0 is partially eliminated;

3) quantitative and qualitative (increase in funding, which, primarily, is designed to increase the material support of faculty and guaranteed expenditures that ensure the functioning of universities in conditions of low quality higher education);

4) innovation-oriented (balanced development of higher education, the material base of universities, the introduction of modern information and communication technologies by improving the quality of higher education and, accordingly, increasing its funding, both through government agencies and private institutions, international funds);

For example, Ukraine is characterized by the second strategic priority, according to which the amount of financial resources allocated to universities by both the state and private sources is relatively low, which significantly prevents quality improvement at the appropriate level, and funding is focused solely on providing wages, the amount of which is not motivating.

At the same time, the best option for Ukraine in the current period is a gradual improvement of quality through the introduction of public-private partnership, development of flexible regulatory support for financial injections into higher education and the ability to fulfill orders as paid services, which will further improve quality. higher education without significant financial infusions from the state and the basement for the fourth strategic priority - innovationoriented, which provides for the balanced development of higher education by improving the quality of higher education and increasing its funding, both through government and private institutions, international funds , positioning of universities as full-fledged and integral participants of cluster development of territories, innovative shifts of economy.

However, when choosing this priority, significant sectoral and regional asymmetries and imbalances should be taken into account. After all, based on the preliminary analysis, there is an uneven distribution of universities in Ukraine, in particular the separation of flagship universities in the world rankings and regional universities that are not popular among applicants, so we consider it appropriate to distinguish marketing strategies of universities in such possible areas.
The penetration strategy is a strategy for most higher education institutions seeking to increase the number of students within the relevant (regional or national) market. Expanding market penetration is the most obvious strategy, its usual practical expression is the desire to increase the number of students. We believe that this strategy is typical, first of all, for regional universities.

The main disadvantage of this strategy of individual universities for higher education in general is that it is achieved mainly through the use of marketing tools during campaigning or by reducing the price of educational services, thus imitating this strategy in the development.

Market development strategy means the adaptation and introduction of existing educational services on the market of educational services for foreign applicants, ie the implementation of their export. For the successful implementation of the strategy it is necessary to confirm the presence of a contingent of foreign applicants seeking to receive such services. The main risk of such a strategy may be the lack of potential customers and the mismatch of services - needs. Regarding the aspect of the potential market of foreign applicants, then the universities of Ukraine, in particular technical and medical education, are considered as attractive for foreign citizens; the increase in the student body is mainly due to the independent influx of foreign students (reasonable price and availability of nostrification agreements).

However, it should be noted that in recent years, due to the unstable situation in the country (wax conflicts) and the refusal to nostrify the diplomas of Ukrainian universities, the strategy of "passive waiting" is less effective.

The implementation tool is the introduction of Englishlanguage teaching, which increases the influx of foreign applicants.

Product development strategy - the offer on the existing market of new specialties or specializations, the possibility of double diplomas and the possibility of foreign internships. This strategy is typical for the country's leading universities. The diversification strategy is the most costly and risky strategy used to exhaust the opportunities for growth in existing markets, change market conditions, which is typical for Ukraine (departure of Ukrainian applicants abroad, in connection with the choice of more prestigious foreign universities), profitable opportunities and the high potential benefits of capturing a new market. Such a strategy within the framework of the development of the state mechanism can be applied in part, only to universities with a special status - universities that have entered the international rankings.

Thus, we believe that the isolation of separate marketing strategies, along with scenarios of strategic priorities will allow the most accurate direction of the existing opportunities of the university to increase their competitiveness, in particular, and higher education in general.

\section{Conclusion}

Thus, the Industrial Revolution 4.0 does not leave aside either the economy as a whole or the sphere of higher education, as the latter provokes the corresponding transformations, which are prerequisites for the further development of any sphere in the modern conditions. First of all, the appropriate transformations should be carried out in the field of higher education, given the key role of the tertiary sector in building an effective innovation economy and prospects for society as a whole. 


\section{References}

1. Ph. Brown, R. Scase. Higher Education and Employment in Post-Industrial Society. The Student's Companion to Sociology. - Oxford: Blackwell Publ. (1997)

2. Algeria Wages. URL:

https://radingeconomics.com/algeria/wages

3. Education at a Glance 2016: OECD Indicators. URL: http://download.eiie.org/Docs/WebDepot/EaG2016_EN.pdf

4. D. Bell. Notes on the Post-Industrial Society. The Public Interest. 7, (1967)

5. D. Bell. The Coming of PostIndustrial Society: A Venture in Social Forecasting. New York: Basic Book. Factories of the Future. URL: https:/www.effra.eu/sites/default/files/factori es of the future 2020 roadmap.pdf (1973)

6. From Industry 4.0 to Society 5.0: the big societal transformation plan of Japan. URL:

https:/www.i-scoop.eu/industry-4-0- society-5-0/.

7. Germany: Industrie 4.0. URL:

https://ec.europa.eu/growth/tools-databases/ $\mathrm{dem} / \mathrm{monitor} /$ sites/default/files/DTM_Industri e\%204.0.pdf.

8. Horizon 2020. URL: https:// ec.europa.eu/programmes/horizon2020/en/.

9. J. Raven. Competence in Modern Society: Its Identification, Development and Rebase. Toronto: University of Toronto (1984)

10. K. Schwab. The fourth industrial revolution. What it means and how to respond. URL: https://www.foreignaffairs.com/articles/2015-1212/fourthindustrial-revolution 